\title{
One step paired electrochemical synthesis of iron and iron oxide nanoparticles
}

\author{
JULIET ORDOUKHANIAN $^{1, *}$, HASSAN KARAMI $^{1,2}$, AZIZOLlah NEZHADALI $^{1}$ \\ ${ }^{1}$ Department of Chemistry, Payame Noor University, PO Box 19395-3697, Tehran, Iran \\ ${ }^{2}$ Nano Research Laboratory, Department of Chemistry, Payame Noor University, Abhar, Iran
}

\begin{abstract}
In this study, a new one step paired electrochemical method is developed for simultaneous synthesis of iron and iron oxide nanoparticles. Iron and iron oxide are prepared as cathodic and anodic products from iron (II) sulfate aqueous solution in a membrane divided electrolytic cell by the pulsed current electrosynthesis. Because of organic solvent-free and electrochemical nature of the synthesis, the process could be considered as green and environmentally friendly. The reduction of energy consumption and low cost are the other significant advantages of this new method that would have a great application potential in the chemical industry. The nanostructure of prepared samples was characterized by Fourier transform infrared spectroscopy (FT-IR), X-ray diffraction (XRD), scanning electron microscopy (SEM) and transmission electron microscopy (TEM). The magnetic properties were studied by vibrating sample magnetometer (VSM).
\end{abstract}

Keywords: nanoparticles; electrodeposition; pulsed current method; paired electrosynthesis; magnetic materials

(C) Wroclaw University of Technology.

\section{Introduction}

Electrosynthesis is a powerful tool for a clean synthesis without any additional chemical reagents. But in the most of the processes, the product in one of the compartments is undesirable. In paired electrochemical synthesis, the ability of synthesis of both compounds at the same time led to a considerable reduction of energy consumption and especially the cost. This method has always been important in commercial electrosynthesis processes. There are some examples of paired electrosynthesis such as the synthesis of ethylene and oxalic acid from acetylene [1] or transformation of glucose to gluconic acid and sorbitol [2].

Iron and iron oxides are widely used nanomaterials in various fields, including catalysts, pigments, coatings, gas sensors, sorbents in water and wastewater treatments, magnetic data storage devices in electronics, audio and video recording and drug delivery in medicine [3, 4]. There are various methods to prepare iron and iron oxide

*E-mail: ordoukhanian@pnu.ac.ir nanoparticles such as chemical precipitation [5, 6], thermal decomposition of organometallic compounds [7, 8], gas phase condensation [9], solgel [10], microemulsion [11] and electrochemical techniques $[12,13]$. However, some of these methods require higher temperature and pressure and require complex process and technology.

The shape and size of nanoparticles produced by various methods can vary depending on the conditions and methods of synthesis. In electrosynthesis, the concentration of electrolyte and current density affect the size and morphology of nanoparticles. The current can be applied in pulse mode. The pulsed current decreases the nucleation growth and increases the nucleation rate, therefore decreases the size of nanoparticles [14].

In the present work, two widely used nanoparticles of iron and iron oxide were obtained at the same time by the pulsed current electrochemical method using a membrane divided electrochemical cell and iron (II) sulfate aqueous solution as a starting material. The composition, size and morphology of the synthesized samples were characterized by FT-IR spectroscopy, XRD, SEM, TEM 
and VSM studies. The method has been found to be simpler, efficient, clean and energy saving, which could have a potential for industrial application.

\section{Materials and methods}

The pulsed current electrosynthesis was carried out using the power supply and pulse generating apparatus (BTE 06) made by Karami Technical Group in Iran. The electrochemical cell consisted of two stainless steel (316L) electrodes with $12 \mathrm{~cm}^{2}$ active surface area in a solution of $\mathrm{FeSO}_{4}$ as precursor and $\mathrm{AgNO}_{3}$ as nucleation starter. The temperature was controlled in the Pars Azma water bath (Iran). The solution was stirred mechanically with stainless steel rods. Iron and iron oxide nanoparticles were synthesized in a divided electrolytic cell with a glass membrane. Iron was produced in cathode and iron oxyhydroxide of $\mathrm{FeOOH}$ (goethite) was obtained in anode, respectively. Goethite was transformed to the most stable phase of iron oxide $\alpha-\mathrm{Fe}_{2} \mathrm{O}_{3}$ (hematite) through the thermal transformation by annealing at $400{ }^{\circ} \mathrm{C}$ for two hours.

The structures of synthesized nanoparticles were identified by FT-IR Shimadzu Prestige 21 and XRD Shimadzu 6000 using $\mathrm{CuK} \alpha$ incident radiation. The SEM Hitachi 4160 and TEM Philips EM208 were used for studying the morphology and the particle size. All SEM images were analyzed by microstructure measurement software to determine the average particle size. The saturation magnetization of the nanoparticles was determined by VSM Lake Shore 7200. All chemicals were reagent grade from Merck and used without further purification.

\section{Results and discussion}

In the one step paired pulse current galvanostatic synthesis of $\mathrm{Fe}$ and $\alpha-\mathrm{Fe}_{2} \mathrm{O}_{3}$, there are some parameters such as pulse current amplitude, pulse time, relaxation time, concentration of iron salt and temperature of the solution. The values of the mentioned parameters were optimized during experiments by the "one at a time" method to produce smaller and more uniform nanoparticles. The pulse currents from
$10 \mathrm{~mA} \times \mathrm{cm}^{-2}$ to $60 \mathrm{~mA} \times \mathrm{cm}^{-2}$ were applied to the electrochemical cell. The SEM analyses showed that the particle size of the nanoparticles increased when the pulse current increased above $20 \mathrm{~mA} \times \mathrm{cm}^{-2}$. The pulse frequency varied from 10 $\mathrm{Hz}$ to $18 \mathrm{~Hz}$ at a constant ratio of $\mathrm{t}_{\mathrm{off}} / \mathrm{t}_{\mathrm{on}}=3$. Based on the previous studies [15], this ratio was suitable to synthesize iron oxide nanoparticles by pulse current method. The particle size decreased when the pulse frequency increased from $10 \mathrm{~Hz}$ to $14 \mathrm{~Hz}$, but at higher frequencies, the relaxation time was too short to allow the nucleation growth and the particle size was increased. Varying iron sulfate concentration from $0.002 \mathrm{~mol} \times \mathrm{L}^{-1}$ to $0.010 \mathrm{~mol} \times \mathrm{L}^{-1}$ caused that the lower concentration of iron salt created smaller and more uniform nanoparticles. Then syntheses were carried out at different temperatures of $25^{\circ} \mathrm{C}, 45^{\circ} \mathrm{C}, 75^{\circ} \mathrm{C}$ and $95^{\circ} \mathrm{C}$. At higher temperature, the electrosynthesis performance was higher. Therefore, the electrosynthesis was carried out under the optimum conditions of the pulse current at $20 \mathrm{~mA} \times \mathrm{cm}^{-2}$, frequency of $14 \mathrm{~Hz}$, pulse time $\mathrm{t}_{\mathrm{on}}=18 \mathrm{~ms}$ and relaxation time $\mathrm{t}_{\mathrm{off}}=54 \mathrm{~ms}$ in a solution of $0.002 \mathrm{~mol} \times \mathrm{L}^{-1} \mathrm{FeSO}_{4}$ at $95{ }^{\circ} \mathrm{C}$. The SEM and TEM images of iron and iron oxide nanoparticles synthesized in the optimized conditions are shown in Fig. 1. In the SEM analysis the samples were in powder form and in the SEM images there are actually cactus-shaped particles containing spherical nanoparticles attached to each other. In TEM analysis, the powder was distributed in ethanol by ultrasonic waves. So the cactus-shaped particles were broken down and the almost spherical nanoparticles were released. The distribution of particle size in SEM analysis ranged from $22 \mathrm{~nm}$ to $39 \mathrm{~nm}$ for iron and $62 \mathrm{~nm}$ to $80 \mathrm{~nm}$ for iron oxide. The precise average size showed in TEM images of spherical nanoparticles was $30 \mathrm{~nm}$ for iron and $70 \mathrm{~nm}$ for iron oxide.

The chemical structure of the synthesized iron oxide nanoparticles was characterized by FT-IR spectra. In Fig. 2 the spectra show that these particles are made of $\mathrm{FeOOH}$, which further transformed thermally to $\alpha-\mathrm{Fe}_{2} \mathrm{O}_{3}$. The goethite shows two hydroxyl stretching bands at $3450 \mathrm{~cm}^{-1}$ and $3206 \mathrm{~cm}^{-1}$, one intensive hydroxyl bending 

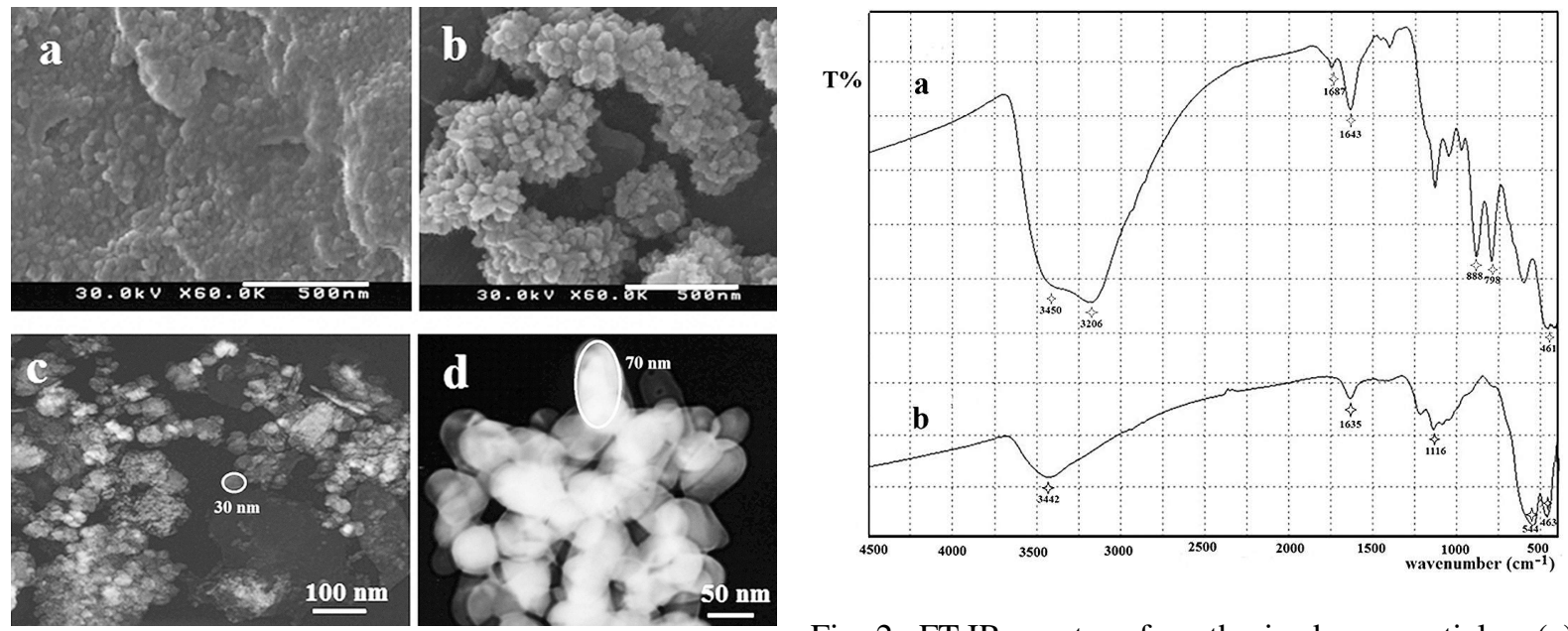

Fig. 1. SEM images of synthesized nanoparticles: (a) iron, (b) iron oxide, and TEM images: (c) iron, (d) iron oxide.

band at $1643 \mathrm{~cm}^{-1}$, two hydroxyl deformation bands at $888 \mathrm{~cm}^{-1}$ and $798 \mathrm{~cm}^{-1}$, one hydroxyl translation band at $619 \mathrm{~cm}^{-1}$ and one $\mathrm{Fe}-\mathrm{O}$ vibration at $465 \mathrm{~cm}^{-1}$. The characteristic IR vibrations of $\alpha-\mathrm{Fe}_{2} \mathrm{O}_{3}$ at $463 \mathrm{~cm}^{-1}$ and $544 \mathrm{~cm}^{-1}$ could be observed during the thermal transformation of goethite to hematite, which relates to the bending and stretching vibrations of $\mathrm{Fe}-\mathrm{O}$ bond [16]. The absorption peak at $3442 \mathrm{~cm}^{-1}$ indicates the presence of $\mathrm{OH}$ group which can be assigned to the surface $\mathrm{OH}^{-}$ions on the iron oxide particles. The peaks at $1635 \mathrm{~cm}^{-1}$ and $1116 \mathrm{~cm}^{-1}$ may be attributed to $\mathrm{O}-\mathrm{H}$ bending vibrations combined with $\mathrm{Fe}$ atom.

The structure and composition of the nanoparticles were characterized by XRD. Fig. 3 shows the XRD patterns of synthesized iron and iron oxide samples. The intensive diffraction peak at $2 \theta$ of $44^{\circ}$, characteristic of iron, comes from diffraction of ( $\left.\begin{array}{lll}1 & 1 & 0\end{array}\right)$ plane. A small peak from $\left(\begin{array}{lll}2 & 0 & 0\end{array}\right)$ plane is observed at $2 \theta$ of $64^{\circ}$, which is in accordance with (JCPDS\# 85-1410). The narrow and high intensity peaks show that the sample has crystallized and the average size estimated from Scherrer's formula is $28 \mathrm{~nm}$. The nanostructure nature of the iron oxide is evident from the broadness of the peaks in XRD patterns. All diffraction peaks at $2 \theta$ of $24^{\circ}, 33^{\circ}, 36^{\circ}, 41^{\circ}, 49^{\circ}, 54^{\circ}, 58^{\circ}, 62^{\circ}$,

Fig. 2. FT-IR spectra of synthesized nanoparticles: (a) goethite and (b) hematite.

$64^{\circ}$ and $72^{\circ}$ were indexed as hematite according to (JCPDS\# 33-0664). The average particle size was estimated using broadening of the most intense peak at $2 \theta$ of $33^{\circ}$ that was $80 \mathrm{~nm}$. The average size of the particles was in agreement with the SEM and TEM results.

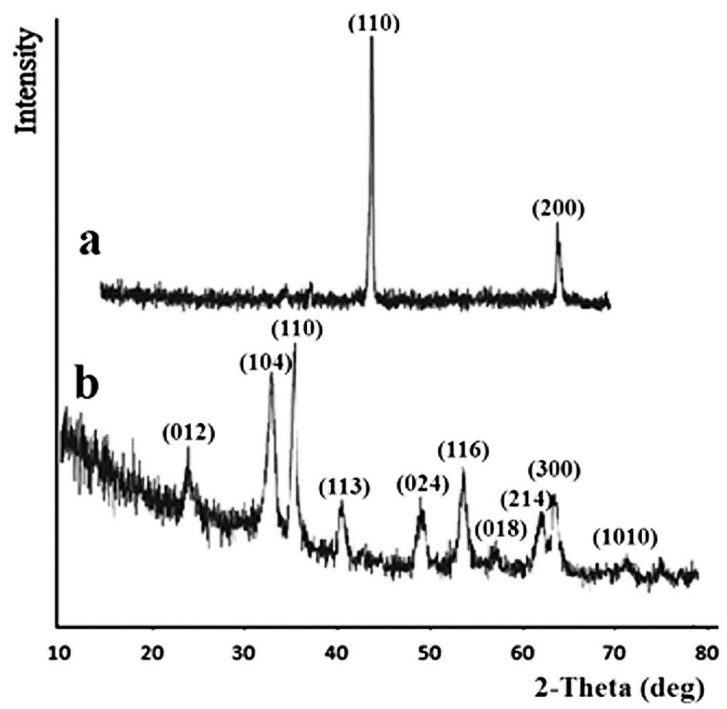

Fig. 3. XRD patterns of synthesized nanoparticles: (a) iron and (b) iron oxide.

Because of special electrical and magnetic properties of iron, which is ferromagnetic, and iron oxide, which is weakly ferromagnetic, these nanoparticles have a variety of applications [3, 4]. The saturation magnetization $\left(\mathrm{M}_{\mathrm{s}}\right)$ of nanoparticles 
depends on the size and morphology of the particles and at room temperature decreases with reduction of particle size [17]. The magnetic properties of the synthesized nanoparticles were studied by VSM. Magnetization curves at room temperature are shown in Fig. 4. The obtained $\mathrm{M}_{\mathrm{s}}$ values of iron and iron oxide nanoparticles are $130 \mathrm{emu} \times \mathrm{g}^{-1}$, and $75 \mathrm{emu} \times \mathrm{g}^{-1}$, respectively. In comparison to nanoparticles with similar size, they are consistent with the published data (Table 1).

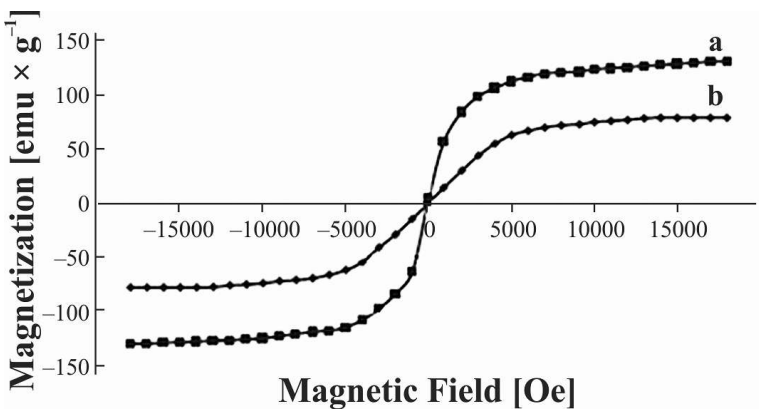

Fig. 4. Magnetization curves of synthesized nanoparticles: (a) iron and (b) iron oxide.

Table 1. Comparison of VSM results of synthesized nanoparticles with published data.

\begin{tabular}{ccccc}
\hline \multirow{2}{*}{$\begin{array}{c}\text { Nanoparticle } \\
\text { Morphology }\end{array}$} & $\begin{array}{c}\text { Size } \\
{[\mathrm{nm}]}\end{array}$ & $\begin{array}{c}\mathrm{M}_{\mathrm{s}} \\
{\left[\mathrm{emu} \times \mathrm{g}^{-1}\right]}\end{array}$ & Reference \\
\hline \hline Iron & coreshell & $<44$ & 132 & {$[18]$} \\
& & 10 & 60 & \\
& spherical & 30 & 130 & This work \\
Hematite & subrounded & 87 & 72 & {$[19]$} \\
& & 36 & 8.6 & \\
& spherical & 70 & 75 & This work \\
\hline
\end{tabular}

\section{Conclusions}

This work presents a new method to synthesize $\mathrm{Fe}$ and $\alpha-\mathrm{Fe}_{2} \mathrm{O}_{3}$ nanoparticles in $\mathrm{FeSO}_{4}$ aqueous solution by one step paired pulsed current electrosynthesis. The synthesis of two compounds at the same time, using one starting material reduces the energy consumption, waste and the cost. This method can be considered as a green and efficient method.

\section{Acknowledgements}

The authors gratefully acknowledge the financial support of this work (Project No: 89003321) by the Iran National Science Foundation (INSF) and the Payame Noor University Research Council.

\section{References}

[1] Song X., Du H., Liang Z., Zhu Z., Duan D., LIU S., Int. J. Electrochem. Sci., 8 (2013), 6566.

[2] Park K., Pintauro P.N., Baizer M.M., Nobe K., J. Electrochem. Soc., 132 (1985), 1850.

[3] Kharisov B.I., Rasika Dias H.V., Kharissova O.V., Jimenez Perez V.M., Perez B.O., Flores B.M., RSC Adv., 2 (2012), 9325.

[4] Mohapatra M., Anand S., Int. J. Eng. Sci. Tech., 2 (2010), 127.

[5] Sun Y.P., Li Q.X., Zhang W., Wang H.P., Colloid. Surface. A, 308 (2007), 60.

[6] CHEN Y.H., Li F.A., J. Colloid. Interf. Sci., 347 (2010), 277.

[7] Wang P., Li H., Du Z., Int. J. Electrochem. Sci., 8 (2013), 4712.

[8] Li Z., Lai X., Wang H., MaO D., Xing C., WANG D., Nanotechnology, 20 (2009), 245603.

[9] Wu R., XIE C., Mater. Lett., 57 (2003), 1539.

[10] Pawar M.J., Khajone A.D., Ingale A.B., GAONAR M.D., Int. J. Adv. Sci. Res. Tech., 2 (2012), 600.

[11] OKoli C., SAnChez-Dominguez M., Boutonnet M., Jaras S., Civera C., Solans C., KutTUVA G.R., Langmuir, 28 (2012), 8479.

[12] Yoo B.Y., Hernandez S.C., Koo B., Rheem Y., MYUNG N.V., Water Sci. Technol., 55 (2007), 149.

[13] Schrebler R., Llewelyn C., Vera F. Cury P., Munoz E., Rio R., Electrochem. Solid-State Lett., 10 (2007), D95.

[14] Spanou S., PaVlatou E.A., J. Appl. Electrochem., 40 (2010), 1325.

[15] Karami H., Chidar E., Int. J. Electrochem. Sci., 7 (2012), 2077.

[16] Kolhatkar A.G., Jamison A.C., Litvinov D., Willson R.C., LEE T.R., Int. J. Mol. Sci., 14 (2013), 15977.

[17] Raming T.P., Winnubst A.J.A., van Kats C.M., PhILIPSE A.P., J. Colloid Interf. Sci., 249 (2002), 346.

[18] Yusmartini E.S., Setiabudidaya D., Adv. Mater. Res., 1112 (2015), 62.

[19] Zhang Y.C., Tang J.Y., He X.Y., J. Alloy. Compd., 462 (2008), 24. 